\title{
Acromioclavicular Joint Pain among Secondary School Students in Lahore, Pakistan
}

\section{Shoaib Waqas ${ }^{1}$, Naseem Ahmad Siddique ${ }^{2}$, Muzna Munir ${ }^{3}$}

\author{
${ }^{1}$ Assistant Professor Lahore College of Physical Therapy, LMDC, Lahore \\ 2 Senior physiotherapist, Social Security Teaching hospital, Multan road, Lahore \\ ${ }^{3}$ Physiotherapist, Boston Physiotherapy and wellness Clinic, Lahore
}

Author's Contribution

2 Conception and design, Collection and assembly of data, ${ }^{1}$ Analysis and interpretation of the data, Statistical expertise, ${ }^{3}$ Drafting of Article, Critical revision of the article for important intellectual content, Final approval and guarantor of the article.

Article Info.

Received: Nov 11, 2020

Acceptance: June 11, 2021

Conflict of Interest: None

Funding Sources: None

Address of Correspondence

Dr Muzna Munir

Email Id:muznafmh@gmail.com

Cite this article as: Waqas $\mathrm{S}$, Siddique NA, Munir M. Acromioclavicular Joint Pain among Secondary School Students in Lahore, Pakistan. JRCRS. 2021; 9(1). 31-35. DOI:

https://dx.doi.org/10.53389/JRCRS.20 $\underline{21090107}$
A B S T R A C T

Background: The education system in Pakistan is putting physical exertion on students among which is the impact of bag carrying practice which every student has to undergo. Heavy loading of the spine may induce musculoskeletal problems in children. When it comes to musculoskeletal problems, acromioclavicular joint pathology is assumed to be among top of list according to some surveys reported. Frequent overloading of school bags carried by students in primary and secondary schools is the main reason. This Study is conducted to find out facts associated with it.

Objective: To determine the acromioclavicular joint pain among secondary school students. Methodology: Data was collected from 370 secondary school students. The convenience sample technique was used for selection of schools. The self-designed questionnaire was used with combination of Paxinos test, Saccomanni (SAC) test and Numeric Pain Rating Scale (NPRS) as data collection tool. The data was analyzed in SPSS 20.0. The study time period was seven months.

Results: Results regarding location of shoulder pain showed there were $16.2 \%$ students complaining unilateral shoulder pain, $10 \%$ bilateral shoulder pain and $73.8 \%$ were not feeling any pain in shoulders. History of onset of shoulder pain showed $13.5 \%$ of students were having pain from more than 30 days, $12.7 \%$ from less than 30 days while rest of $73.8 \%$ were not complaining pain. Results regarding sitting showed that $73 \%$ students were sitting on bench, $17 \%$ on single arm chair and $10 \%$ were sitting in double arm chair. Paxinos Test was positive in $21.4 \%$ for right shoulder and $5.9 \%$ for left shoulder. SAC test was positive in $16.8 \%$ students for right shoulder and 6.8 for left shoulder. Numeric Pain Rating Scale showed overall mild pain or discomfort in $86.8 \%$ students and $13.2 \%$ students with moderate pain.

Conclusion: The study concludes that there was mild level of acromioclavicular joint pain in secondary school students where right shoulder was found to be affected more in comparison to left shoulder. Furthermore, the bag weight to body weight ratio was above the minimum recommended guidelines.

Keywords: Bag-Packs, Physical Therapy, School Bag, Secondary School.

\section{Introduction}

One of common cause leading to shoulder pain includes pathology of acromioclavicular joint. There are many other disorders leading to shoulder pain with symptoms similar to that of acromioclavicular joint pathology. Due to diverse location of pain origin from acromioclavicular joint, often patients are not able to pin point it acromioclavicular joint and it comes to notice in clinical examination. Mostly the pain pattern lies around insertion of deltoid and middle of clavicle. Although pathology of acromioclavicular joint can occur in isolation, however, it can accompany impingement syndrome with or without rotator cuff syndrome. ${ }^{1}$ In recent studies, 
prevalence of shoulder pain among musculoskeletal (MSK) disorders in school student is $22 \%$ in Bosnia Herzegovina, $11.5 \%$ in Netherlands, $41.1 \%$ in China. ${ }^{2} \mathrm{~A}$ study was conducted by Sahara through magnetic resonance imaging in dynamic mode evaluated acromioclavicular joint movement in relation arm. It was shown that maximum clavicle translation at acromion end in posterior direction takes place at 90 degrees of shoulder abduction. This is probably due anterolateral attachment of deltoid at lateral clavicular end. According to the study, that traction pull of deltoid muscle produces effect in posterior direction and cause all this translation. In case of advance of ranges of abduction, the deltoid produces anterior pull on acromion. ${ }^{3}$

Usually, injuries related to acromioclavicular joint take place due to direct blow or fall on arm in an abducted position resulting direct blow to point of acromion. Severity of such an injury depends on direction and force. This injury can range from small sprain of ligament to its tear and instability of acromioclavicular joint with or without coraco-acromial ligament. The direction and degree of acromioclavicular was classified later by Rockwood and Green. ${ }^{4}$ There is a general consensus for the non-surgical treatment of type 1 and type 2 lesions of Rockwood and Green classification. Initially non-surgical treatment is recommended even for type 3 lesions and operative interventions for Rockwood type 4 to 6 lesions is recommended. ${ }^{5}$ Surgical techniques include primary stabilization of the AC joint with pins, wires and screws, muscle- tendon transfer operations and clavicle resection with CC stabilization. ${ }^{6}$ Physical therapy for AC joint pathology include cross-fiber massage, ROM exercises, joint gliding and joint mobilization techniques. ${ }^{6}$ There is a lot of evidence in literature to support that MSK complaints in school going student are due to heavy school bags. These bags are considered as one of the universal risk factors contributing to MSK pain in school student. Most commonly affected areas in school student carrying heavy bags are shoulder, back and neck regions. ${ }^{7}$

There is a lack of research conducted in this regard to study the pathology of individual involvement of these four joints of the shoulder region among secondary school student due to heavy school bags up till now. Most studies accessing recurrent or chronic pain conditions in children have been limited to descriptions of discomfort and pain intensity. In Pakistan, literature review has revealed no previous study describing Acromioclavicular joint pain among secondary school student. So, the purpose of this study is to describe the Acromioclavicular joint pain individually among secondary school student in Lahore, Pakistan.

\section{Methodology}

Descriptive Cross sectional survey was conducted and Data was collected from Secondary Schools of Lahore, Pakistan. Duration of the study was seven months after the approval of synopsis. A sample size of 370 was calculated by the given formula with margin of error $5 \%$, level of significance $95 \%$ and population proportion $38 \% .^{8}$ Convenience sampling was used for the selection of schools and students.

Inclusion criteria was Students from secondary schools, age from 11 to 18 years, both genders and who can ambulate easily and independently. In addition, parental and pupil consent was also taken. Male and female students were taken with height difference of \pm 5 $\mathrm{cm}$ and weight difference of $\pm 5 \mathrm{~kg}$. All the students of with associated congenital, acquired, pathological deformities were excluded. All the students of having history or medical record of accidental trauma or fall and neoplastic tissues are also excluded. All the students of age under 11 and above 18 years. Students must not have any sports related activities or such evening jobs in previous six months which can cause AC joint pathology.

After taking permission from parents, students, school authorities and university authorities, students with pain in shoulder region were selected to test for the Acromio-clavicular joint pathology by using Paxinos test, Saccomanni (SAC) test. Then pain level was analyzed by Numeric pain rating scale (NPRS). Data was analyzed by SPSS 23. Age, body mass index, height, weight and scores of the students were presented in the form of mean and standard deviation. While the qualitative categorical variables such as gender, trend of bag carrying, location of pain, and extended probe investigating other musculoskeletal problems were presented in frequency tables and pie charts. 


\section{Results}

The descriptive results regarding age found as mean \pm standard deviation to be $14.04 \pm 0.84$ years. Other descriptive statistics of quantitative measurements for school bag, weight, height and body mass index is mentioned in the table (Table no I). The results regarding gender, class or grade are mentioned in (Table no II) along with school bag carrying duration and position on shoulder.

\begin{tabular}{|c|c|}
\hline $\begin{array}{ll}\text { Table I: } & \text { Descriptive } \\
\text { Measurements } & \end{array}$ & Statistics Quantitative \\
\hline Variable & Mean \pm Std. Deviation \\
\hline Age & $14.04 \pm 0.84$ \\
\hline School Bag Weight & $6.03 \pm 0.85$ \\
\hline Body Weight & $53.72 \pm 3.99$ \\
\hline $\begin{array}{l}\text { Percentage of School Bag } \\
\text { Weight }\end{array}$ & $11.28 \pm 1.78$ \\
\hline Height & $1.65 \pm 0.03$ \\
\hline Body Mass Index & $19.74 \pm 1.57$ \\
\hline \multicolumn{2}{|c|}{ Table II: Frequency/ Percentages Demographics } \\
\hline Variable & N (Percentage) \\
\hline \multicolumn{2}{|l|}{ Gender } \\
\hline Male & $194(52.4 \%)$ \\
\hline Female & $176(47.6 \%)$ \\
\hline \multicolumn{2}{|c|}{ Students' Class/ Grade } \\
\hline 9th Class & $180(48.6 \%)$ \\
\hline 10th Class & $190(51.4 \%)$ \\
\hline \multicolumn{2}{|c|}{ Body Mass Index Category } \\
\hline Underweight & $33(8.9 \%)$ \\
\hline Normal & $335(90.54 \%)$ \\
\hline Overweight & $02(0.54 \%)$ \\
\hline \multicolumn{2}{|c|}{ School Bag Carrying Duration } \\
\hline 5 Minutes & $122(33.0 \%)$ \\
\hline 5-10 Minutes & $47(12.7 \%)$ \\
\hline 11-20 Minutes & $48(13.0 \%)$ \\
\hline 21-30 Minutes & $77(20.8 \%)$ \\
\hline$>30$ Minutes & $76(20.5 \%)$ \\
\hline \multicolumn{2}{|c|}{ School Bag Position on Shoulder } \\
\hline Right & $184(49.7 \%)$ \\
\hline Left & $61(16.5 \%)$ \\
\hline Both & $125(33.8 \%)$ \\
\hline
\end{tabular}

Results regarding location of shoulder pain, onset of pain and sitting position are shown in Table no Illwith other diagnostic test for acriomioclavicular joint. Hence paxinos test was positive in $21.4 \%$ of population and SAC test was positive in $16.8 \%$ with right shoulder. While applying on left shoulder, paxinos test was positive in $5.9 \%$ of population and SAC test was positive in $6.8 \%$ of population. Numeric Pain Rating Scale showed overall mild pain or discomfort in $86.8 \%$ students and $13.2 \%$ students with moderate pain.

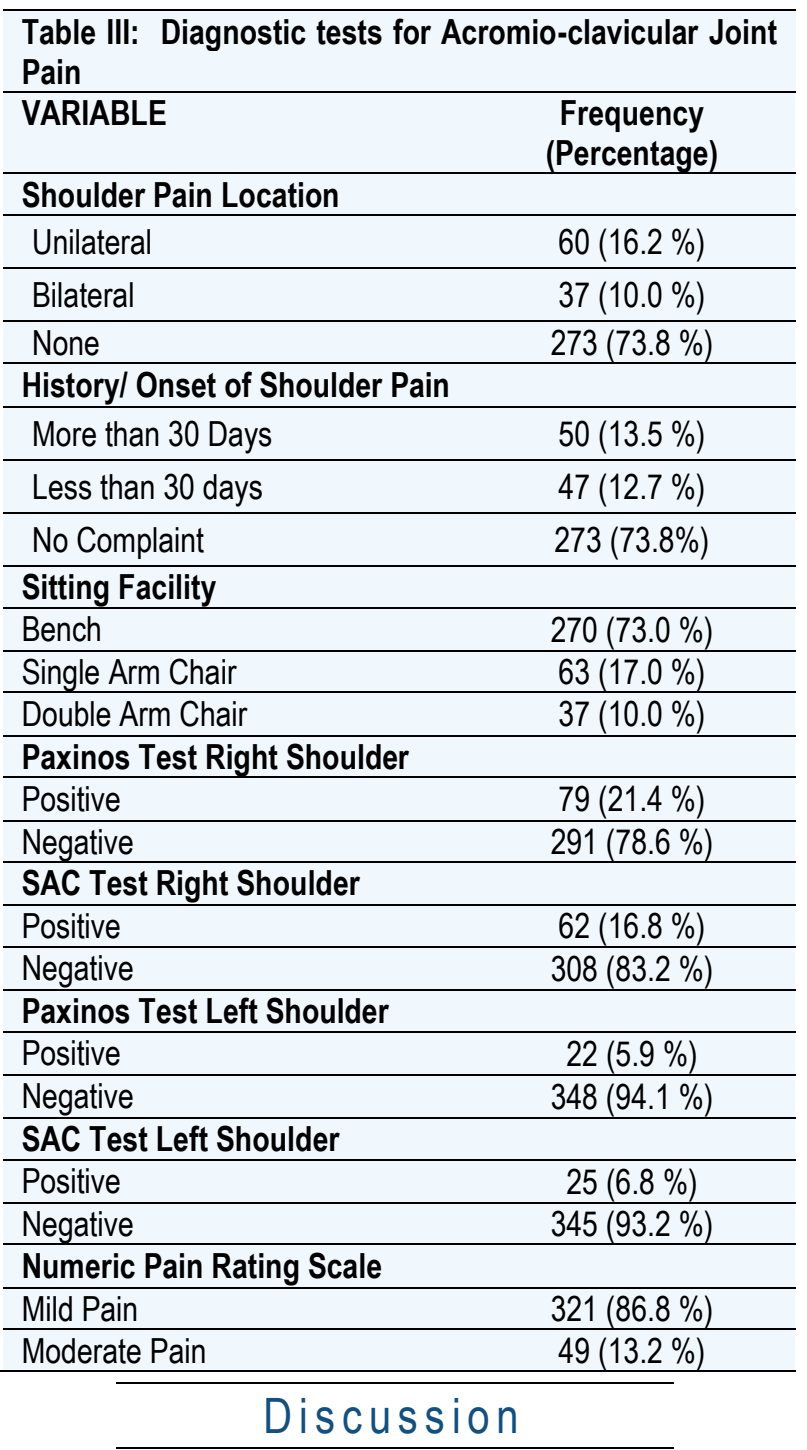

The findings of study showed overall mild level of pain in acromioclavicular. The demographics showed that on average age was adolescence. This is age of higher metabolic rates and students are engaged in high energy activities which often mask accessory problems. Weight of school bag was varied and so does of students. On average students were neither overweight nor underweight. Most students were in normal body mass index. Although, school bag weight to body weight ratio was not high, but it was found above borderline margin of minimum recommended ratio. Both genders were equally 
included in survey, although boys were slightly more than girls may be due situational advantage were boys were easily approachable for data collection. All of subjects were in normal body weight index, rather there was a small ratio falling in underweight category. This may be due to fact that congenital obesity and students with other such problems were excluded because they were likely to affect outcomes.

Yi lang et al have conducted an experiment on school children. The research focuses on low back pain due to heavy bags carried by students. The study had discussed the posture with heavy bag packs but the results showed there was no significant relationship between the two variables regarding low back pain. While Kimberly D. Dahl et al concludes in his study that heavy bag packs can eventually lead to poor posture and multiple problems. Hence they are significantly correlated with each other and there are no studies accessing specifically acromioclavicular joint pathology in children. However some studies are on adolescents.

Although school bag carrying duration were among all responses asked, the majority were carrying bag for less time, most likely because students use convince such as car or other way of transportation and they don't have to carry in a literal manner. The carrying shoulder was right in majority students and so does the involvement because the shoulder pain location was right in majority and high number of students didn't complain. Those who complained, had stated it experiencing from more than 30 days thus of chronic nature. 9-12

This current study survey was extended to dig out adjunct musculoskeletal problems in students. The sequence of involvement from highest to least was neck, back, shoulder, wrist, elbow, ankle, and hip and knee region. This rate was extracted on basis of pain experienced now a days with a simple 'yes' or 'no'. The respondents were cross questioned with verbal rating pain scale which showed all student experiencing pain without exception, although intensity for majority was mild. The ratio of student's weight to bag pack was surprisingly almost equally distributed in every category. There were less students with normal ratio while majority were having different levels of overweight. Half of students were having alarmingly high ratio which means they are subject to higher weights of bag. ${ }^{13-16}$
There should be measure to check extra weight carried by student in number of steps. The homework notebooks should be checked regular to pull from bags. The schedule should be checked for each day so that student carry only required books for that day. Furthermore, the administration should take measures for keeping stuff in school that is not to be used at home. However, smaller range included student who were only going from home to school vehicle or vehicle to school and same in reverse. However, there was still a time taken in waiting and standing for school vehicle and van, which could not be measured. ${ }^{17-21}$

Postural structure disturbances were associated with longer time for watching TV and gaming because of bad postural position. We found no link between postural structure disturbances and using double-band backpacks because most students used such backpacks and thus a sample size of students used single-band backpacks were low leading lowering the power of study. The ratio of the weight of bag to students' body weight higher than $10 \%$ was associated with the risk for postural structure disturbances in that was similar to previous studies. Postural structure disturbances was more frequent in those without pain because appearing pain has a protective role and thus tend the students to change their position for reliving the pain. We also found an association between the rate of postural structure disturbances (especially shoulder pain, shoulder asymmetry, kyphosis), and weight of backpacks indicating a central role of weight on occurring these abnormalities.(22-25)

\section{Conclusion}

Mild level of acromioclavicular joint pain in bag carrying secondary school student where right shoulder found affected more in comparison to left shoulder. Furthermore, the bag weight to body weight ratio was above the minimum recommended guidelines. In an extended probe during survey, it was revealed that other musculoskeletal problems were also prevalent of which the reported were pain or discomfort in wrist, neck, back and ankle. There should be guidelines development for parents, teachers and school administration regarding awareness about postural and structural impairments caused due improper ergonomics and backpacks. The 
books or items not in use should be kept in school lockers or common lock so that it be not carried every time around. Roller bags can also be used.

References

1. Walton J, Mahajan S, Paxinos A, Marshall J, Bryant $C$, Shnier $R$, et al. Diagnostic values of tests for acromioclavicular joint pain. The Journal of Bone \& Joint Surgery. 2004;86(4):807-12.

2. Azabagic S, Spahic R, Pranjic N, Mulic M. Epidemiology of Musculoskeletal Disorders in Primary School Children in Bosnia and Herzegovina. Materia socio-medica. 2016;28(3):164.

3. Sahara W, Sugamoto K, Murai M, Tanaka H, Yoshikawa $\mathrm{H}$. 3D kinematic analysis of the acromioclavicular joint during arm abduction using vertically open MRI. Journal of orthopaedic research. 2006;24(9):1823-31.

4. Antonio GE, Cho JH, Chung CB, Trudell DJ, Resnick D. MR imaging appearance and classification of acromioclavicular joint injury. American Journal of Roentgenology. 2003;180(4):1103-10.

5. Beitzel K, Cote MP, Apostolakos J, Solovyova O, Judson $\mathrm{CH}$, Ziegler CG, et al. Current concepts in the treatment of acromioclavicular joint dislocations. Arthroscopy: The Journal of Arthroscopic \& Related Surgery. 2013;29(2):387-97.

6. Houglum PA. Therapeutic Exercise for Musculoskeletal Injuries 4th Edition: Human Kinetics; 2016.

7. Ranganathan DSMMR, clude1 Jessin AM, Kavoor J, editors. A systematic review of risk factors for musculoskeletal pain due to heavy backpacks in school children. Proceedings 19th Triennial Congress of the IEA; 2015.

8. Shamsoddini A, Hollisaz M, Hafezi R. Backpack weight and musculoskeletal symptoms in secondary school students, Tehran, Iran. Iranian journal of public health. 2010;39(4):120.

9. Alghadir AH, Gabr SA, Al-Eisa ES. Mechanical factors and vitamin $D$ deficiency in schoolchildren with low back pain: biochemical and cross-sectional survey analysis. Journal of pain research. 2017;10:855.

10. Arghami S, Moshayedi M, Ziad IR. Multi-Purpose Ergonomic Backpack for High School Students. J Hum Environ Health Promot. 2016;1(3):159-65.

11. Ayesha HS, Rehman SSU. Prevalence and Associated Risk Factors of Spinal Pain Among School Going Young Children. Journal of Riphah College of Rehabilitaion Sciences. 2017;5(1):37-41.

12. Calvo-Muñoz I, Kovacs FM, Roqué M, Gago Fernández I, Seco Calvo J. Risk Factors for Low Back Pain in Childhood and Adolescence. The Clinical journal of pain. 2018;34(5):468-84.

13. Chen YL, Mu YC. Effects of backpack load and position on body strains in male schoolchildren while walking. PloS one. 2018;13(3):e0193648.
14. Chiwaridzo M, Naidoo N. Differences in personal and lifestyle characteristics among Zimbabwean high school adolescents with and without recurrent non-specific low back pain: a two part cross-sectional study. Archives of physiotherapy. 2015;5(1):13.

15. Dahl KD, Wang H, Popp JK, Dickin DC. Load distribution and postural changes in young adults when wearing a traditional backpack versus the BackTpack. Gait \& posture. 2016;45:90-6.

16. Fonseca CD, dos Santos AC, Candotti CT, Noll M, Luz $\mathrm{AMH}$, Corso $\mathrm{CO}$. Postural education and behavior among students in a city in southern Brazil: student postural education and behavior. Journal of physical therapy science. 2015;27(9):2907-11.

17. Kim CY, Jeong HW, Kim HD. Changes of Center of Pressure and Cadence Analysis According to the Carrying Type and Weight of a Bag in College Students. Journal of the Korea Academia-Industrial cooperation Society. 2015;16(3):2012-9.

18. Macedo AC, Morais AV, Martins HF, Martins JC, Pais SM, Mayan OS. Match between classroom dimensions and students' anthropometry: re-equipment according to european educational furniture standard. Human factors. 2015;57(1):48-60.

19. Malik M, Vinay D, Pandey K. Effect of backpack weight on postural angles in pre-adolescence school children. International Journal of Education and Management Studies. 2017;7(1):34.

20. Mohammed K, Cadogan A, Robinson D, Roche J. The shoulder in the collision athlete. Orthopaedics and Trauma. 2015;29(3):195-205.

21. Møller SP, Brauer C, Mikkelsen S, Alkjær T, Koblauch H, Pedersen EB, et al. Risk of subacromial shoulder disorder in airport baggage handlers: combining duration and intensity of musculoskeletal shoulder loads. Ergonomics. 2018;61(4):576-87.

22. Hardie R, Haskew R, Harris J, Hughes G. The effects of bag style on muscle activity of the trapezius, erector spinae and latissimus dorsi during walking in female university students. Journal of human kinetics. 2015;45(1):39-47.

23. Hyung EJ, Lee HO, Kwon YJ. Influence of load and carrying method on gait, specifically pelvic movement. Journal of physical therapy science. 2016;28(7):2059-62.

24. Kamper SJ, Henschke N, Hestbaek L, Dunn KM, Williams $\mathrm{CM}$. Musculoskeletal pain in children and adolescents. Brazilian journal of physical therapy. 2016(AHEAD):.

25. Kamper SJ, Yamato TP, Williams CM. The prevalence, risk factors, prognosis and treatment for back pain in children and adolescents: an overview of systematic reviews. Best Practice \& Research Clinical Rheumatology. 2016;30(6):1021-36. 